\title{
Nota sobre Matayba livescens stat. nov. (Sapindaceae, Cupanieae) do litoral brasileiro
}

\author{
A note on Matayba livescens stat. nov. (Sapindaceae, Cupanieae) from the Brazilian coast
}

\author{
Rubens Luiz Gayoso Coelho ${ }^{1,2}$, Vinicius Castro Souza ${ }^{1,2} \&$ María Silvia Ferrucci $^{3}$
}

\begin{abstract}
Resumo
Matayba livescens stat. nov. é segregada de Matayba guianensis f. livescens, reconhecida como uma espécie distinta e inserida na sect. Matayba. Caracteres que separam as espécies são discutidos neste trabalho. São apresentados aqui uma descrição morfológica, diagnose, ilustração e comentários sobre a taxonomia e distribuição geográfica da espécie.
\end{abstract}

Palavras-chave: Matayba sect. Matayba, Matayba livescens, Sapindaceae, litoral brasileiro.

\begin{abstract}
Matayba livescens stat. nov. is segregated from Matayba guianensis f. Livescens; it is raised to species level, and placed in sect. Matayba. Distinguishing characteristics of related species are discussed. Description, diagnosis, illustration and comments on geographic distribution are provided.
\end{abstract}

Key words: sect. Matayba, Matayba livescens, Sapindaceae, new status.

\section{Introdução}

O gênero Matayba é um dos maiores e mais relevantes dentro da tribo Cupanieae (Radlkofer 1879, 1934), compreende cerca de 56 espécies restritas a região neotropical ocorrendo desde o México até o norte da Argentina e no Brasil onde apresentam 31 espécies, sendo 17 endêmicas, ocorrendo em diversos tipos vegetacionais.

Entre os gêneros da tribo Cupanieae, Cupania L. é o que apresenta maior relação morfológica com Matayba, compartilhando numerosos caracteres sinapomórficos (Somner \& Ferrucci 2004). Em Matayba, as sépalas estão unidas, formam um cálice cupular, e 5-lobado, enquanto em Cupania o cálice apresenta 5 sépalas livres. Outra característica que distingue estes dois gêneros é a precoce abertura do cálice nos botões florais em Matayba, enquanto este caráter não ocorre em Cupania.

Radlkofer (1934) separou as espécies de Matayba em quatro seções, sendo Matayba sect. Matayba a maior seção do gênero com 17 espécies distribuídas apenas na América do Sul. No Brasil, esta seção ocorre predominantemente fora da região Amazônica com exceção de Mataya guianensis
Aubl., com uma ampla distribuição e Matayba atropurpurea Radlk. na Amazônia brasileira e colombiana. Outras espécies, como por exemplo, Matayba elaeagnoides Radlk., em adição a sua distribuição no Brasil, ocorre também no Paraguai e norte da Argentina.

Após o tratamento realizado por Radlkofer (1934), a seção Matayba apresenta apenas uma nova espécie apresentada por Reitz (1980), para a Flora de Santa Catarina. Conhecendo este fato, o tratamento mais completo para o gênero Matayba continua sendo o de Radlkofer (1934) em sua monografia sobre a família.

Durante a preparação da dissertação de Mestrado sobre Matayba sect. Matayba, este novo status foi encontrado pelos autores do presente trabalho.

\section{Material e Métodos}

O presente estudo foi realizado e baseado em revisão bibliográfica, em trabalhos realizados no campo e na análise dos materiais depositados nos seguintes herbários: ESA, GUA, HB, MBM, SP, SPF, SPSF, R, RB e UEC.

\footnotetext{
${ }^{1}$ Universidade Estadual de Campinas, Inst. Biologia, C.P. 6109, 13083-970. Campinas, SP, Brazil. e-mail: binhoht@hotmail.com

${ }^{2}$ Universidade de São Paulo, Escola Superior de Agricultura "Luiz de Queiroz”, C.P. 9; 13418-900, Piracicaba, SP. e-mail: vcsouza@esalq.usp.br.

${ }^{3}$ Instituto de Botánica del Nordeste, C.C. 209, 3400, Corrientes, Argentina. e-mail: msferrucci@yahoo.com.ar
} 


\section{Resultados}

Matayba livescens (Radlk.) R.L.G. Coelho, Souza \& Ferrucci, comb. nov.

Fig. 1a-g

Basiônimo: Matayba guianensis f. livescens Radlk., Sitzungsber. Math.-Phys. Cl. Königl. Bayer. Akad. Wiss. München 4: 633. 1879. Lectótipo (aqui designado): Brasila, Bahia, Wawra \& Maly n.126 (W), syn. nov.

Matayba guianensis f. livescens subf. macrosperma Sitzungsber. Math.-Phys. Cl. Königl. Bayer. Akad. Wiss. München 4: 633. 1879. Brasila, Bahia, Wawra \& Maly n.126 (W), syn. nov.

Arbustos a árvores, 2-8 m alt.; ramos cilíndricos a lateralmente achatados, subglabros a pubérulos. Folhas distribuídas por todo o ramo; pecíolo cilíndrico a subcilíndrico, 2,6-4,5 cm compr., subglabro a pubérulo; raque cilíndrica a bicanaliculada, 1,7-10,9 cm compr., subglabra a esparsamente pubescente. Folíolos 4-10; $3,8-14,6 \times 1,4-6,2 \mathrm{~cm}$, alternos a subopostos, subsésseis a peciolulados, peciólulos $0,4-1 \mathrm{~cm}$ compr., subcilíndricos a canaliculados, pubérulos; coriáceos, elípticos, largamente elípticos, elípticooblongos, elíptico-ovados a ovados; conduplicados, recurvados, ápice agudo, base aguda, atenuada ou raro obtusa, assimétrica; margem revoluta, inteira, discolores, subglabros a esparsamente pubescentes em ambas as faces, tricomas adpressos; venação broquidódroma, fracamente proeminente na face superior folíolos, reticulação aberta, nervura central proeminente a plana na face superior, subglabra a esparsamente pubescente em ambas as faces; nervuras secundárias levemente proeminentes na face superior, 6-12 pares, geralmente retilíneas a levemente arqueadas; domácias ausentes. Inflorescências axilares, paniculiformes; ultrapassando o tamanho das folhas em comprimento, pedúnculo cilíndrico, 4,5-17,1 cm compr., sulcado, pubérulas a densamente pubescentes, raque cilíndrica a achatada lateralmente, $6-21,5 \mathrm{~cm}$, sulcada a profundamente sulcada, pubérulas a densamente pubescentes, brácteas $2-3 \mathrm{~mm}$ compr., triangularlanceoladas, pubescentes, bractéolas semelhantes e menores que as brácteas, menores; pedicelo floral ca. 2-3 mm compr., articulado na região basal, pubescente a densamente pubescente. Flores 4-5 $\mathrm{mm}$ compr.; sépalas ca. 1,5 $\mathrm{mm}$ compr., unidas na região mediana, ovadas a obovadas, ápice obtuso a arredodando, pubérulas a pubescentes externamente, tricomas estrigosos, pubescente internamente, emaranhados; margem ciliada; pétalas 1-1,5 mm compr., largamente espatulado a largamente obovadas, ápice arredondado, podendo ser irregular a truncado, unhas de $0,2-0,4$ $\mathrm{mm}$ compr., subglabras externamente, lanosas internamente; apêndice petalífero basal menor, igual ou maior que as pétalas, podendo ultrapassar o tamanho em largura, lanoso; disco nectarífero glabro; flores masculinas com estames 3-4 mm compr., filetes filiformes, retos, geralmente de tamanhos iguais, raro diferentes na mesma flor, densamente pubescentes até a região mediana, sendo geralmente pubescentes a glabros na apical, anteras glabras a raro subglabras, oblongas a oblongoobovadas, pistilódio ca. $1 \mathrm{~mm}$ compr., rombóide, densamente pubescente; flores femininas com gineceu 4-5 mm compr., ovário ovado, bicarpelares ou tricarpelares, levemente lobado, densamente pubescente; estilete 1-2 mm compr., fortemente lobado, lobos do estigma unidos, proeminentes; esparsamente pubescente, estaminódios ca. 2,0 mm compr., filetes inteiramente pubescentes. Cápsulas $0,9-1,9 \times 0,5-2 \mathrm{~cm}$, subglobosas, fortemente lobadas, estípite ca. $2 \mathrm{~mm}$ compr., remanescentes do cálice presentes, apiculados, bicarpelares a tricarpelares, geralmente (1-)3-seminadas; pericarpo subcoriáceo, verrucoso a tuberculado, subglabro a densamente pubérulo; endocarpo densamente tomentoso. Sementes elipsóides a obovadas, $1-1,4 \times 0,9-1,1 \mathrm{~cm}$, negras; arilo esbranquiçado recobrindo a região basal da semente.

Os indivíduos pertencentes a esta espécie encontram-se nos estados brasileiros da Bahia, Espírito Santo e Rio de Janeiro, sempre nas florestas de restinga, em dunas semi-fixas ou na transição para áreas periodicamente alagadas.

Encontrada com flores nos meses de outubro, dezembro a abril e junho, e com frutos nos meses de outubro, dezembro a abril e no mês de junho. Material examinado: BRASIL. ESPÍRITO SANTO: Praia de Itaóca, 22.I.1984, fr., G.V. Somner et al. 424 (GUA). Vila Velha, Rodovia do Sol, ca. $22 \mathrm{~km}$ após Guarapari, 5.III.2001, fl., P. Fiaschi et al. 653 (SPF, SP). RIO DE JANEIRO: Araruama, restinga da Praia Seca, 20.XII.1982, fl. e fr., G.V. Somner 303 (GUA). Cabo Frio, Arraial do Cabo, restinga entre Lagoa de Araruama e praia de Massambaba, 28.III.1978, fr., G. Martinelli 4110 (RB); Tucuns, 25.III.1993, fr., $L$. Emídio \& R. Lampaso 5710 (R); praia de Massambaba, terras da Álcalis, 14.VI.1984, fl., D.S.D. Araújo et al. 6340 (GUA); Reserva Ecológica Estadual de Massambaba, 26.X.1993, fl. e fr., G.V. Somner 484 (RB); Massambaba, a $40 \mathrm{~km}$ da praia de Iguaba e a $15 \mathrm{~km}$ do trevo de Cabo Frio, 5.II.1986, fl., Fontella 
et al. 2287 (RB); praia de Massambaba, 14.I.1986, fl. e fr., D.S.D. Araújo 7146 (GUA); sistema de dunas Dama Branca, 13.I.1988, fl. e fr., D.S.D. Araújo 8392 (GUA); área da CIA, Salinas Perynas, 18.III.1989, fr., C. Farney 2280 (RB). Casimiro de Abreu, restinga da Praia Virgem, 31.I.1999, fl. e fr., R.N. Damasceno 723 (RB). Macaé, Lagomar, 9.V.1995, fl., D.S.D. Araújo \& B. Kurtz 10254 (GUA); restinga de Cabiúnas, 19.I.1984, fl., G.V. Somner et al. 417 (GUA); Macaé, mata de Cardão, 30.I.1997, fr., V. Capello 38 (HB). Rio das Ostras, Mar do Norte, rodovia Amaral Peixoto, km 163, 18.II.2003, fr., H.C. de Lima et al. 6072 (RB); Reserva Biológica União, 20.X.1997, fl. e fr., P. P. de Oliveira 313 (BHCB); 21.III.1979, fr., P. P. Jouvin 443 (RB).
Saquarema, Reserva Ecológica de Jacarepiá, cordão arenoso na área da mata em regeneração, 12.XII.1990, fl. e fr., D.S.D. Araújo 9217 (GUA); 12.II.1992, fr., D.S.D. Araújo 9591 (GUA); 2.VII.1998, fr., D.S.D. Araújo 10275 (GUA); Restinga de Ipitangas, 23.I.1987, fr., C. Farney et al. 1374 (RB); Restinga de Ipitangas, 20.XII.1988, fl., C. Farney et al. 2216 (RB); Reserva Ecológica Jacarepiá, 11.XII.1990, fl., C. Farney 3240 et al. (GUA, RB); Reserva Ecológica Estadual de Jacarepiá, VIII-XII.1993, fl., C. Farney et al. 3787 (RB); Jacomé, 29.III.2000, fr., C. Farney et al. 3997 (RB); Reserva Ecológica Estadual de Jacarepiá, 21.I.1993, fl., J. Fontella et al. 2885 (RB); Praia de Itaunas, 25.IV.1987, fr., H.C. de Lima et al. 2835 (RB).
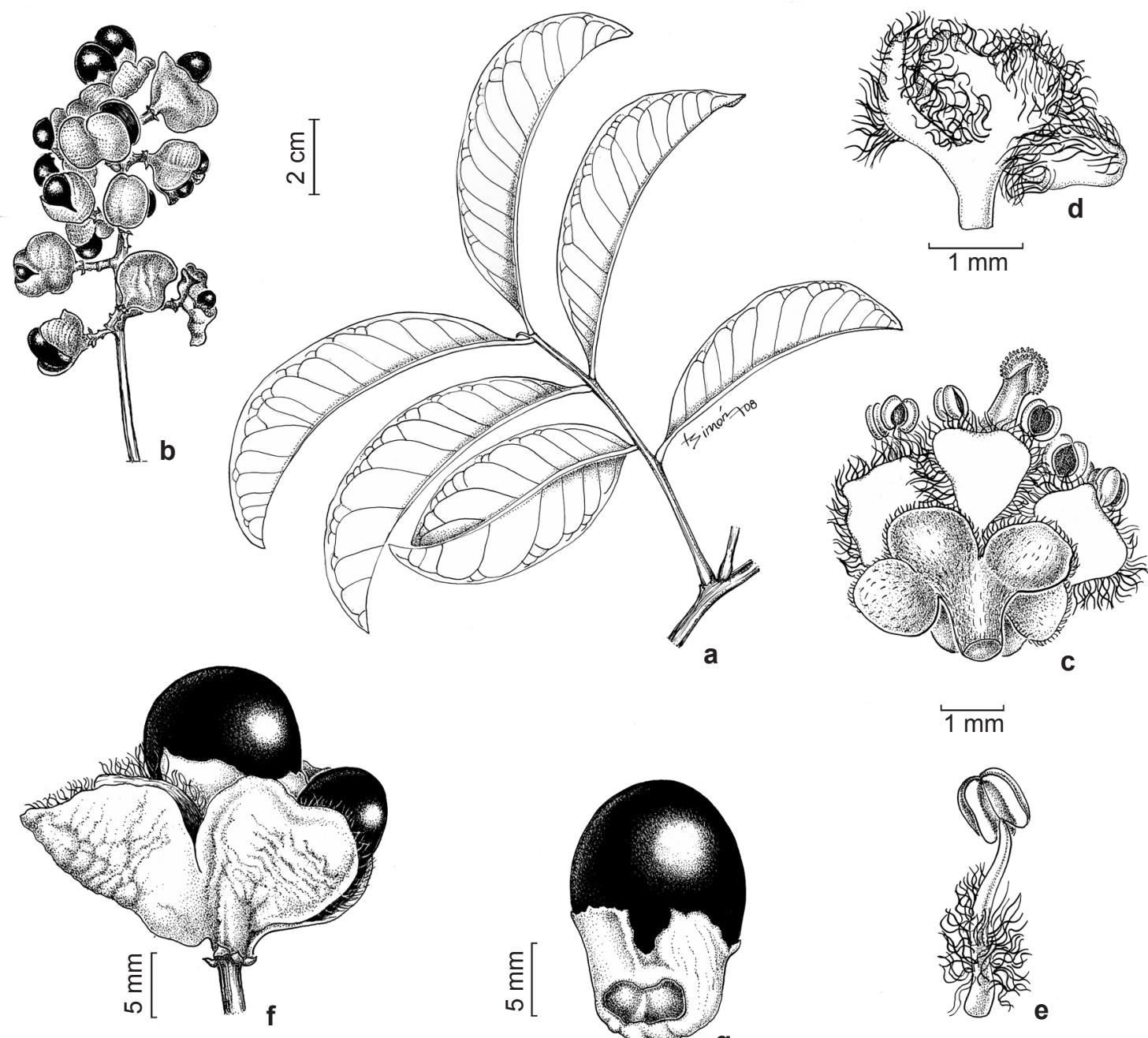

a
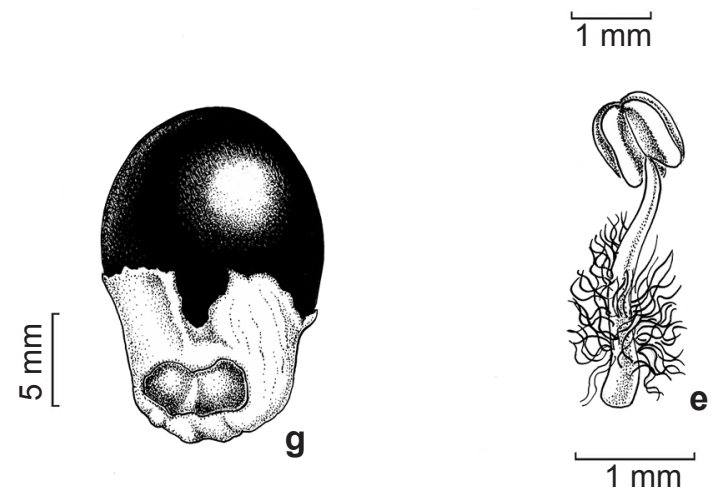

Figura 1 - Matayba livescens - a. ramo; b. infrutescência; c. flor feminina com estaminódios; d. pétala, face interna; e. estaminódio da flor feminina; f. fruto; g. semente, face ventral. (a, c-e Araujo 9217, GUA; b, f-g Araujo et al. 9591, GUA). Figure 1 - Matayba livescens - a. branch; b. infrutescence; c. female flower with staminodes; d. petal, inner surface; e. staminode of female flower; f. fruit; g. seed, ventral surface. (a, c-e Araujo 9217, GUA; b, f-g Araujo et al. 9591, GUA). 


\section{Discussão}

Previamente identificada em sua grande maioria apenas como Matayba guianensis, esta espécie é agora denominada Matayba livescens (Radlk.) R.L.G. Coelho, Souza \& Ferrucci, principalmente devido ao fato de ser reconhecida por Radlkofer (1934) como uma das formas de $M$. guianensis (M. guianensis f. livescens).

Agora reconhecida como uma espécie distinta, tendo como epíteto específico o nome da forma de atribuída por Radlkofer (1934), esta espécie tem sua identidade relacionada a alguns caracteres que lhe conferem tal modificação. As semelhanças entre esta duas espécies podem se resumir aos folíolos conduplicados e recurvados, a venação fracamente proeminente em ambas as faces dos folíolos e ao pericarpo dos frutos que geralmente apresenta uma superfície tuberculada. M. livescens é agora reconhecida como uma espécie por apresentar (Tab. 1) folíolos coriáceos, discolores na maioria das vezes com a face superior brilhante, as nervuras secundárias geralmente arqueadas (apesar de aparentarem ser curvadas, devido os folíolos serem conduplicados e recurvados), apenas a nervura central e as nervuras secundárias serem proeminentes na face superior dos folíolos, as nervuras de ordens mais baixas serem planas e finalmente a ausência de domácias, diferenciandose de M. guianensis por esta apresentar (Tab. 1) folíolos cartáceos, concolores, opacos na face superior, nervuras secundárias curvadas e toda a rede de nervuras fracamente proeminente na face superior dos folíolos e na maioria das vezes a presença de domácias foveoladas ou urceoladas nas axilas da nervura central com as secundárias.
Relacionado à fenologia desta espécie, nota-se uma peculiaridade no período entre a floração e a frutificação que na grande maioria dos materiais observados se sobrepõe, apresentando em grande parte das vezes tanto flores como frutos maduros.

Vale a pena ressaltar também que segundo Radlkofer (1934), Matayba guainensis f. livescens apresenta duas subformas (M. guianensis $\mathrm{f}$. livescens subf. verrucosa e $M$. guianensis $\mathrm{f}$. livescens subf. macrosperma) e que essas duas subformas são designadas como sinônimos para M. livescens, já que os caracteres apresentados pelo autor citado acima que diferenciariam essas subformas e a espécie são contínuos.

Outro fato importante que ajuda na afirmação de Matayba livescens como uma nova espécie é sua presença apenas nas florestas de restinga, estando sempre relacionada a áreas sob a influência do oceano, enquanto Matayba guianensis encontrase predominantemente distribuída nos cerrados brasileiros, na floresta amazônica e às vezes em florestas estacionais.

\section{Agradecimentos}

Os autores deste trabalho agradecem L. Simón por cobrir a prancha com as ilustrações botânicas preparadas por M.S. Ferrucci; W. Medina e G. Pieszko por digitalizar as imagens; G.V. Somner pelos valiosos comentários e sugestões sobre a espécie; aos curadores dos herbários que disponibilizaram materiais pertencentes ao gênero Matayba; e finalmente aos revisores com as devidas sugestões científicas e sobre o latim. Este trabalho foi realizado com apoio e bolsa do $\mathrm{CNPq}$, do Consejo Nacional de Investigaciones Científicas y Técnicas

Tabela 1 - Caracteres morfológicos comparativos entre Matayba livescens e M. guianensis. Table 1 - Comparative morphologic characters between Matayba livescens e M. guianensis.

\begin{tabular}{lll}
\hline Caracteres & Matayba livescens & Matayba guianensis \\
\hline Consistência do folíolo & Coriáceo & Cartáceo \\
Coloração da face adaxial do folíolo & Esverdeado e brilhante & Morrom e opaco \\
Nervuras secundárias & Arqueadas, 6-12 pares & Curvadas, $6-14$ pares \\
Ângulos das nervuras secundárias & $50^{\circ}-60^{\circ}$ ou $60^{\circ}-70^{\circ}$ & $40^{\circ}-50^{\circ}$ e $50^{\circ}-60^{\circ}$ \\
$\begin{array}{l}\text { Proeminência da nervação na face adaxial dos } \\
\text { folíolos }\end{array}$ & $\begin{array}{l}\text { Nervura primária e secundárias, } \\
\text { terceárias e de ordens inferiores }\end{array}$ & $\begin{array}{l}\text { Nervura primária e secundárias } \\
\text { proeminentes. Terceárias e de ordens } \\
\text { inferiores planas }\end{array}$ \\
Domácias & $\begin{array}{l}\text { Presentes } \\
\text { Distribuição e ecologia }\end{array}$ & $\begin{array}{l}\text { Espírito Santo e Rio de Janeiro em } \\
\text { florestas de restinga }\end{array}$ \\
\hline
\end{tabular}


(PIP N $\mathrm{N}^{\circ}$ 112-200801-02248), da Universidad Nacional del Nordeste (PI A005-2009) e da Agencia Nacional de Promoción Científica, Tecnológica y de Innovación (ANPCyTUNNE, PICTO 00096).

\section{Referências}

Radlkofer, L. 1879. Sitzungsberichte der MathematischPhysikalischen Classe (Klasse). K.B. Akademie der Wissenschaften, München 4: 630-637.
Radlkofer, L. 1934. Sapindaceae. In: Engler, A. \& Diel, L. (eds.). Das Pflanzenreich Regni Vegetabilis Conspectus. Vol. 4. W. Engelmann, Leipzig. Pp. 1019-1109.

Reitz, R. 1980. Flora Ilustrada Catarinense. Sapindáceas. Vol. 1. Herbário Barbosa Rodrigues, Itajaí. 156p.

Somner, G.V. \& Ferrucci, M.S. 2004. A new species of Cupania L. sect. Trigonocarpus (Sapindaceae) from Brazil. Botanical Journal of the Linnean Society 146: 217-221. 